\title{
Molecular and functional characterization of cold-responsive C-repeat binding factors from Brachypodium distachyon
}

Jae Yong Ryu', Shin-Young Hong ${ }^{1}$, Sin-Hye Jo ${ }^{1}$, Je-Chang Woo ${ }^{2}$, Sangmin Lee ${ }^{1}$ and Chung-Mo Park ${ }^{1,3^{*}}$

\begin{abstract}
Background: Adverse environmental conditions severely influence various aspects of plant growth and developmental processes, causing worldwide reduction of crop yields. The C-repeat binding factors (CBFs) are critical transcription factors constituting the gene regulatory network that mediates the acclimation process to low temperatures. They regulate a large number of cold-responsive genes, including COLD-REGULATED (COR) genes, via the CBF-COR regulon. Recent studies have shown that the CBF transcription factors also play a role in plant responses to drought and salt stresses. Putative CBF gene homologues and their downstream genes are also present in the genome of Brachypodium distachyon, which is perceived as a monocot model in recent years. However, they have not been functionally characterized at the molecular level.

Results: Three CBF genes that are responsive to cold were identified from Brachypodium, designated BdCBF1, $B d C B F 2$, and $B d C B F 3$, and they were functionally characterized by molecular biological and transgenic approaches in Brachypodium and Arabidopsis thaliana. Our results demonstrate that the BdCBF genes contribute to the tolerance response of Brachypodium to cold, drought, and salt stresses by regulating downstream targets, such as DEHYDRIN5.1 (Dhn5.1) and COR genes. The BdCBF genes are induced under the environmental stress conditions. The BdCBF proteins possess transcriptional activation activity and bind directly to the promoters of the target genes. Transgenic Brachypodium plants overexpressing the BdCBF genes exhibited enhanced resistance to drought and salt stresses as well as low temperatures, and accordingly endogenous contents of proline and soluble sugars were significantly elevated in the transgenic plants. The BdCBF transcription factors are also functional in the heterologous system Arabidopsis. Transgenic Arabidopsis plants overexpressing the BdCBF genes were also tolerant to freezing, drought, and salt stresses, and a set of stress-responsive genes was upregulated in the transgenic Arabidopsis plants.

Conclusions: Taken together, our results strongly support that the BdCBF transcription factors are key regulators of cold stress responses in Brachypodium and the CBF-mediated cold stress signaling pathway is conserved in this plant species. We believe that this study would confer great impact on stress biology in monocot species and could be applied to engineer abiotic stress tolerance of bioenergy grass species.
\end{abstract}

Keywords: Brachypodium distachyon, C-repeat binding factor (CBF), COLD-REGULATED (COR), Abiotic stress tolerance, Arabidopsis thaliana

\footnotetext{
*Correspondence: cmpark@snu.ac.kr

${ }^{1}$ Department of Chemistry, Seoul National University, Seoul 151-742, Korea

${ }^{3}$ Plant Genomics and Breeding Institute, Seoul National University, Seoul

151-742, Korea

Full list of author information is available at the end of the article
}

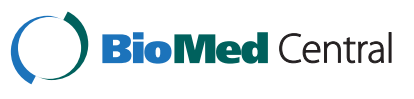

(c) 2014 Ryu et al.; licensee BioMed Central Ltd. This is an Open Access article distributed under the terms of the Creative Commons Attribution License (http://creativecommons.org/licenses/by/2.0), which permits unrestricted use, distribution, and reproduction in any medium, provided the original work is properly cited. The Creative Commons Public Domain Dedication waiver (http://creativecommons.org/publicdomain/zero/1.0/) applies to the data made available in this article, unless otherwise stated. 


\section{Background}

Plants frequently encounter abrupt environmental changes, such as temperature extremes and drought and salt stresses, in their natural habitats. Therefore, they have developed versatile defense mechanisms to cope with adverse growth conditions, which would underlie the astonishing diversity in plant architecture and physiology [1]. Low temperatures severely influence diverse aspects of plant growth and development, resulting in global loss of crop yields and productivity [2,3]. Upon exposure to low temperatures, plants execute a series of adjustments in molecular genetic, physiological, and behavioral processes, which are termed cold acclimation [4].

During the last decade, numerous genes have been identified and functionally characterized in plant response to low temperatures, and underlying molecular mechanisms and signaling schemes have been established in many plant species, mostly in Arabidopsis [5-11]. Cold acclimation enhances plant tolerance to low temperatures by inducing a large set of genes, among which COLDREGULATED (COR) genes are best characterized [6]. The promoters of many COR genes contain one or more copies of the widely conserved cis-acting element, C-repeat/ dehydration response element (CRT/DRE) having the CCGAC core sequence [9], indicating that multiple cold responses are coordinately regulated by common regulators.

It has been shown that a small group of transcription factors, designated C-repeat binding factors (CBFs) that belong to the APETALA2/ethylene-response element binding protein (AP2/EREBP) transcription factor family $[7,8]$, bind directly to the promoters of the COR genes $[8,9]$. The $C B F$ genes are induced under low temperature conditions. The CBF regulation of $C O R$ genes constitutes a major cold signaling pathway, termed the CBF-COR regulon $[7,9,12,13]$, which regulates a wide array of cold response genes. The $C B F$ gene expression is also modulated by upstream regulators. Recent studies have shown that inducer of CBF expression 1 (ICE1), high expression of osmotically responsive gene 1 (HOS1), and MYB15 function upstream of the $C B F$ genes $[11,14,15]$. ICE1 binds to the CBF3 gene promoter to induce gene expression [11]. In contrast, MYB15 binds to the $C B F$ gene promoters, resulting in suppression of the $C B F$ genes [15]. The cold signaling attenuator HOS1 is an E3 ubiquitin ligase that degrades ICE1 and thus compromises extreme cold responses that are harmful to plants [14].

In Arabidopsis, six $C B F$ genes have been identified, among them $C B F 1, C B F 2$, and $C B F 3$ are involved in the regulation of cold-related gene expression [7,9]. These three $C B F$ genes are induced at low temperatures [8]. They are also induced under other abiotic stress conditions, such as drought and high salt $[9,12,13]$. In contrast, the CBF4 gene is not induced at low temperatures but induced under drought and salt stress conditions [10]. Transgenic plants overexpressing $C B F 1$ or $C B F 3$ exhibit improved cold tolerance, and $C O R$ genes are upregulated in the transgenic plants $[9,12]$. Notably, the transgenic plants are also tolerant to salt and drought stresses [13], suggesting that the CBF function is not restricted to cold acclimation. The $C B F 2$ gene has been known as a negative regulator of $C B F 1$ and CBF3 in Arabidopsis [16]. It has been observed that $C B F 2$-deficient mutants are tolerant to cold temperatures, and $C B F 1$ and $C B F 3$ genes are induced in the mutants [16]. It is likely that the expression of $C B F$ genes is elaborately modulated through a negative feedback loop, which may be related with the expression kinetics of the $C B F$ genes: gradual reduction of the transcript levels following the peaks right after cold exposure [16].

Recent molecular genetic and bioinformatic studies indicate that the CBF-COR regulon is conserved in a wide variety of monocots and dicots, such as barley, Chinese cabbage, rice, and wheat [17-23], signifying the physiological significance of cold accumulation in plants under fluctuating temperature conditions. Brachypodium distachyon is a temperate wild grass species that has been explored as a monocot model for studies on wheat and barley because of their genetic and genomic structural similarities [24]. In addition, its morphological and genetic characteristics, relatively well-established molecular tools, and simple growth requirements make it an ideal model system for bioenergy grass biology [25-28]. A potential target of engineering bioenergy grass, such as switchgrass and Miscanthus, is cold stress tolerance, which is intimately linked with grass productivity [29]. However, coldresponsive genes have not been functionally characterized, and related signaling pathways have not been established in Brachypodium as well as in bioenergy grass.

In this study, with an aim of extending our understanding on temperature responses in Brachypodium, we isolated three potential $C B F$ genes $(B d C B F 1, B d C B F 2$, and $B d C B F 3$ ) that are responsive to cold and functionally characterized their roles in abiotic stress responses via transgenic approaches. Similar to the roles of $C B F$ genes in Arabidopsis, the $B d C B F$ genes was induced under various abiotic stress conditions, and transgenic Brachypodium plants were tolerant to cold, drought, and salt stresses. The $B d C B F$ genes were also functional in Arabidopsis, and cold response genes were upregulated in the transgenic Arabidopsis plants that exhibit enhanced tolerance to freezing, drought, and high salt conditions. These observations indicate that the CBF-COR regulon and related cold signaling pathways are conserved in Brachypodium.

\section{Results}

Isolation of $B d C B F$ genes

We searched for key regulators of cold responses in the Brachypodium genome (http://www.brachypodium.org), 
with emphasis on CBF homologues. Through BLAST searches using the Arabidopsis CBF1, CBF2, and CBF3 proteins as baits, we identified 19 potential CBF homologues that have sequence similarities of higher than $50 \%$ throughout the full amino acid sequences to the Arabidopsis CBF proteins (Additional file 1). The identified Brachypodium CBF homologues have residue numbers ranging from 211 to 295 . Recently, it has been shown by microarray assays that many of the Brachypodium $C B F$ genes are cold-responsive [30].

Phylogenetic analysis revealed that the CBF homologues are classified into 4 clades (I to IV), among which 4. CBF homologues belonging to clade IV are somewhat distant from those belonging to clades I to III (Additional file 2). In addition, the clade IV members have not been determined whether they are coldresponsive or not [30]. The CBF homologues belonging to clades I to III were designated BdCBFs (Additional files 1 and 2). Clade I contains a single member (Bradi3g51630.1), which was designated BdCBF1. Clade II contains 2 members: Bradi1g49560.1 was designated BdCBF2, and Bradi1g49570.1 as BdCBF2.1. The other 12 BdCBF members belong to clade III, among which Bradi4g35630.1 was designated BdCBF3, and the other members as BdCBF3.1 to BdCBF3.11.

The AP2 DNA-binding domains of the BdCBF1, $\mathrm{BdCBF} 2$, and BdCBF3 proteins have sequence identities of higher than $70 \%$ with those of monocot CBF proteins (Figure 1A). Phylogenetic analysis revealed that the BdCBF proteins are evolutionally close to those from barley and wheat (Figure 1B), which have been functionally characterized [19,21-23]. The structural conservation and phylogenetic relationship of the CBF proteins would reflect the close genetic relationship between Brachypodium and the small grain cereals [31]. Based the sequence analysis data, we hypothesized that the BdCBF proteins, and related cold signaling pathways as well, would be functionally conserved in Brachypodium.

\section{Binding of BdCBF transcription factors to the promoters of cold-responsive genes}

The CBF proteins function as transcription factors that bind to the CRT/DRE elements of cold-responsive genes in many plant species [21]. We therefore assumed that the BdCBF proteins possess transcriptional activation activity in the regulation of cold-responsive genes in Brachypodium.

We first examined the subcellular localization of the BdCBF1 protein. A green fluorescence protein (GFP)coding sequence was fused in-frame to the $3^{\prime}$ end of the $B d C B F 1$ cDNA sequence, and the BdCBF1-GFP gene fusion was expressed transiently in Brachypodium protoplasts. The results showed that the BdCBF1 protein is localized exclusively in the nucleus (Figure 2A).
We next examined whether BdCBF1 possesses transcriptional activation activity by employing a GAL4 transient expression system in Brachypodium protoplasts [34]. The $B d C B F 1$ cDNA sequence was fused in-frame to the 3 ' end of the GAL4 DNA-binding domain (DB)coding sequence in the effector vector (Figure 2B). The effector vector, the reporter vector having the $\beta$-glucuronidase gene (GUS), and the vector containing the Renilla luciferase gene, which was included as internal control to normalize the measurements, were cotransformed into Brachypodium protoplasts. Measurements of GUS activity showed that BdCBF1 possesses transcriptional activation activity (Figure $2 \mathrm{C}$ ), indicating that it is a transcriptional activator.

The Arabidopsis CBF proteins induce the expression of COR genes by directly binding to the CRT motifs within the gene promoters $[7,8,17]$. We therefore asked whether the BdCBF1 transcription factor binds to the promoter of COR genes. Synthetic nucleotides, which cover the CRT motifs in the promoters of the barley Dhn5.1 and COR14B genes and the Arabidopsis COR15A gene (Additional file 3 ), were analyzed in electrophoretic mobility shift assays (EMSA) using recombinant BdCBF1 protein, which was prepared as BdCBF1-His fusion in Escherichia coli cells. The EMSA assays revealed that BdCBF1 binds to the CRT sequences (Figure 2D). The BdCBF1 binding to the CRT sequences was reduced in the presence of excess amounts (5X) of unlabeled competitor DNA. In addition, the BdCBF1 binding was significantly reduced when mutated CRT sequences were used. These observations indicate that the BdCBF1 transcription factor binds specifically to the CRT sequences in the $C O R$ gene promoters.

\section{Effects of abiotic stresses on $B d C B F$ gene expression}

Monocot and dicot $C B F$ genes are influenced by a variety of abiotic stress conditions, such as cold, drought, and high salinity $[4,5,16,18]$. We found that the BdCBF1 protein is a bona fide transcription factor, which binds to the promoters of cold-responsive genes from Arabidopsis and barley, suggesting that the $B d C B F$ genes would be affected by abiotic stresses.

Two-week-old Brachypodium plants were exposed to various abiotic stress conditions, and total RNA was extracted from whole plants for quantitative real-time RT-PCR (qRT-PCR) assays. Gene expression analysis showed that the $B d C B F 1, B d C B F 2$, and $B d C B F 3$ genes were markedly induced under cold temperature conditions (Figures $3 \mathrm{~A}, \mathrm{~B}$ and $\mathrm{C}$ ). The cold effects were most prominent on the $B d C B F 3$ gene expression with approximately 15 -fold induction. The $B d C B F 1$ and $B d C B F 2$ genes were also induced by drought and high salinity. Whereas the $B d C B F 3$ gene was induced by high salinity, it was not influenced to a detectable level by drought. It is notable 


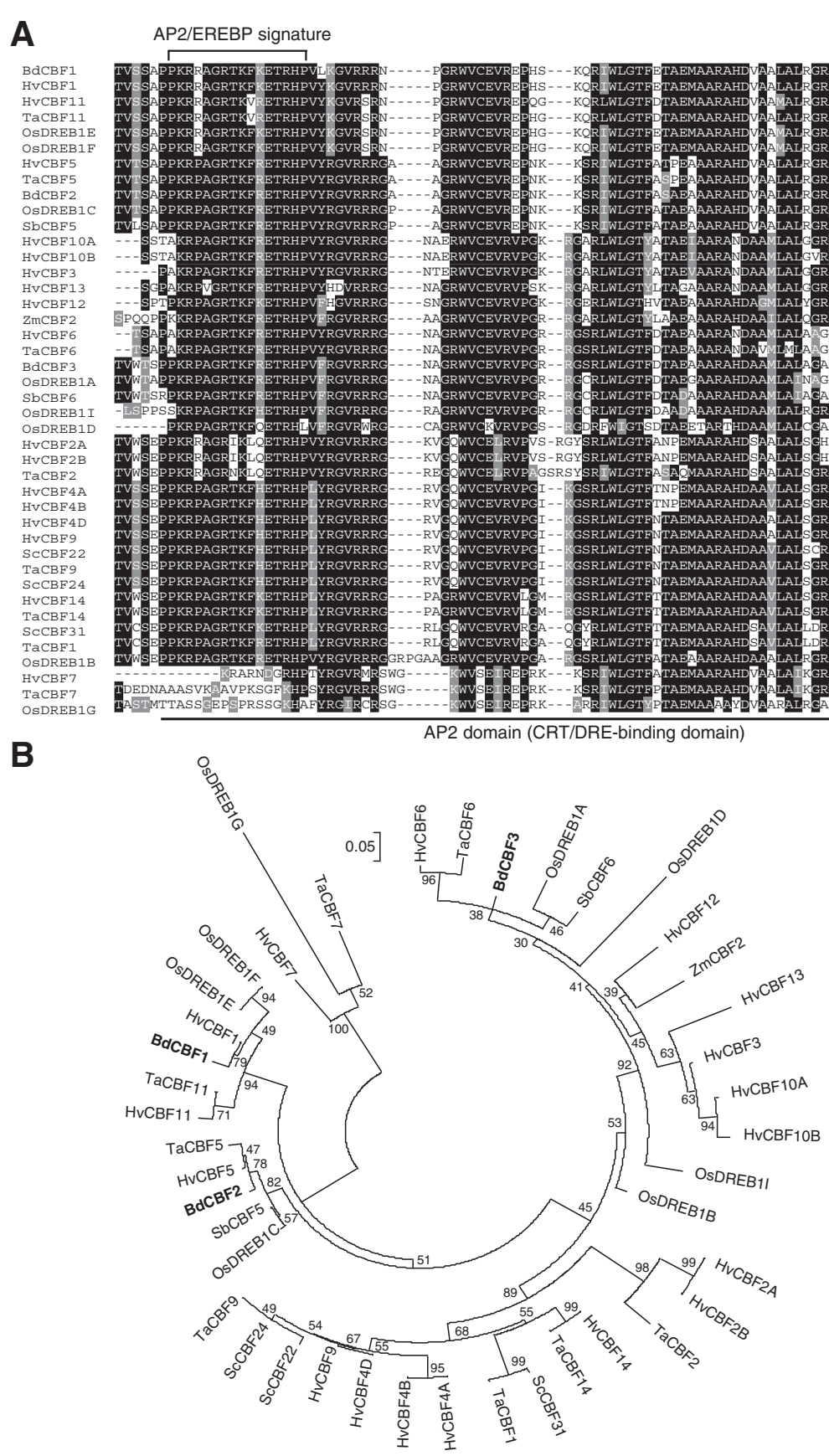

Figure 1 Amino acid sequence comparison of BdCBFs with monocot CBFs. A. Multiple sequence alignment of the AP2 domains of CBF proteins. Amino acid sequences of the AP2 domains were aligned using ClustalX (http://www.clustal.org/clustal2/). Black boxes indicate identical residues, and gray boxes indicate biochemically conserved residues. The AP2/EREBP and DSAWR signature sequences are marked by brackets. Abbreviations for plant species are as follows; Bd, Brachypodium distachyon; Hv, Hordeum vulgare; Os, Oryza sativa; Sb, Sorghum bicolor; Sc, Secale cereale; Ta, Triticum aestivum; Zm, Zea mays. B. Phylogenetic analysis of monocot CBF proteins. The phylogenetic tree was constructed using the MEGA5 software [32]. Bootstrap values (>50\%) based on 1000 replicates are shown.

that the $B d C B F 2$ gene is affected most prominently by high salinity among the abiotic stress conditions examined (Figure 3B). Abscisic acid (ABA), which is a major stress hormone in plants [35], did not have any discernible effects on the $B d C B F$ gene expression, unlike the
CBF gene expression patterns in Arabidopsis and other plant species [5,21]. These observations suggest that the $B d C B F$ genes mediate both cold response and plant responses to drought and salt stress, possibly in an ABA-independent manner. 


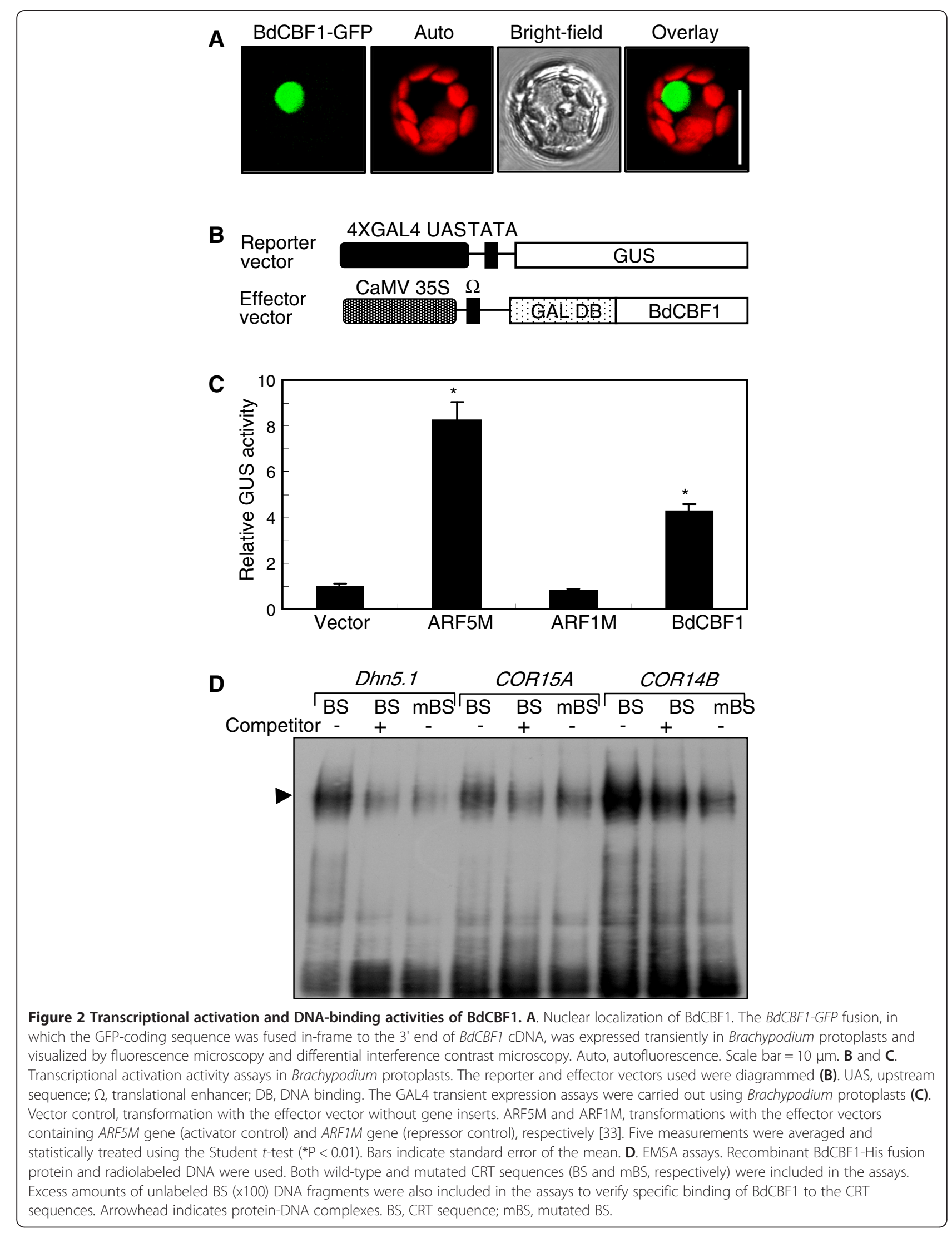



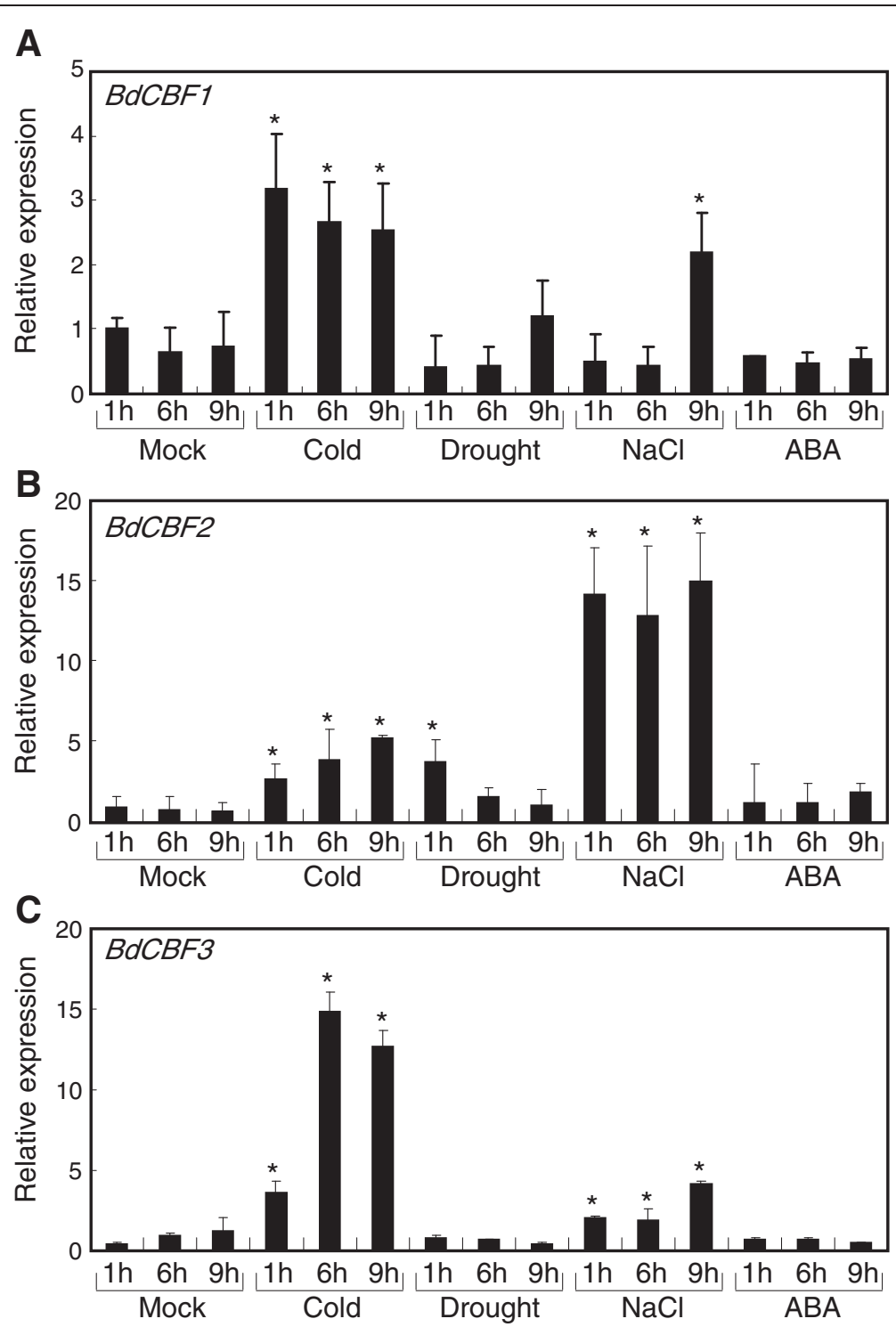

Figure 3 Effects of abiotic stresses on the expression of BdCBF genes. Two-week-old Brachypodium plants grown on MS-agar plates were exposed to cold $\left(4^{\circ} \mathrm{C}\right)$ for the indicated time durations. The plants were also floated in MS liquid media containing either $400 \mathrm{mM}$ mannitol, $300 \mathrm{mM} \mathrm{NaCl}$, or $100 \mu \mathrm{M}$ ABA for the indicated durations. Whole plants were used for the extraction of total RNA samples. Transcript levels were determined by qRT-PCR. Biological triplicates were averaged and statistically treated using the Student $t$-test $\left({ }^{*} P<0.01\right)$. Bars indicate standard error of the mean. $\mathbf{A}$. Effects of abiotic stresses on BdCBF1 gene expression. B. Effects of abiotic stresses on BdCBF2 gene expression. $\mathbf{C}$. Effects of abiotic stresses on $B d C B F 3$ gene expression.

\section{Stress-tolerant phenotypes of BdCBF-overexpressing Brachypodium plants}

Based on the expression analysis of $B d C B F$ genes under abiotic stress conditions, we postulated that the $B d C B F$ genes are associated with plant responses to abiotic stresses.

To investigate the physiological roles of the BdCBF1 transcription factors, the $B d C B F 1$ cDNA sequence was transformed into Brachypodium distachyon ecotype Bd21-3 under the control of the Cauliflower Mosaic Virus (CaMV) $35 \mathrm{~S}$ promoter. The 35S:BdCBF1 transgenic Brachypodium plants were grown under abiotic stress conditions to examine their stress responsiveness.
The 35S:BdCBF1 transgenic plants were phenotypically indistinguishable from the $\mathrm{Bd} 21-3$ control plants except elevated transcription levels of BdCBF1 gene when grown under normal conditions (Figure 4 and Additional file 4). In contrast, they exhibited enhanced tolerance to cold temperatures $\left(4^{\circ} \mathrm{C}\right)$, drought, and salt stress $(300 \mathrm{mM} \mathrm{NaCl})$ (Figures $4 \mathrm{~A}, \mathrm{~B}$ and $\mathrm{C}$, respectively), which is consistent with the inductive effects of the abiotic stresses on the $B d C B F$ gene expression. Electrolyte leakage assays using the leaf blades showed that electrical conductivity was drastically reduced in the leaves of the $35 \mathrm{~S}: B d C B F 1$ transgenic plants that were treated with freezing temperatures 

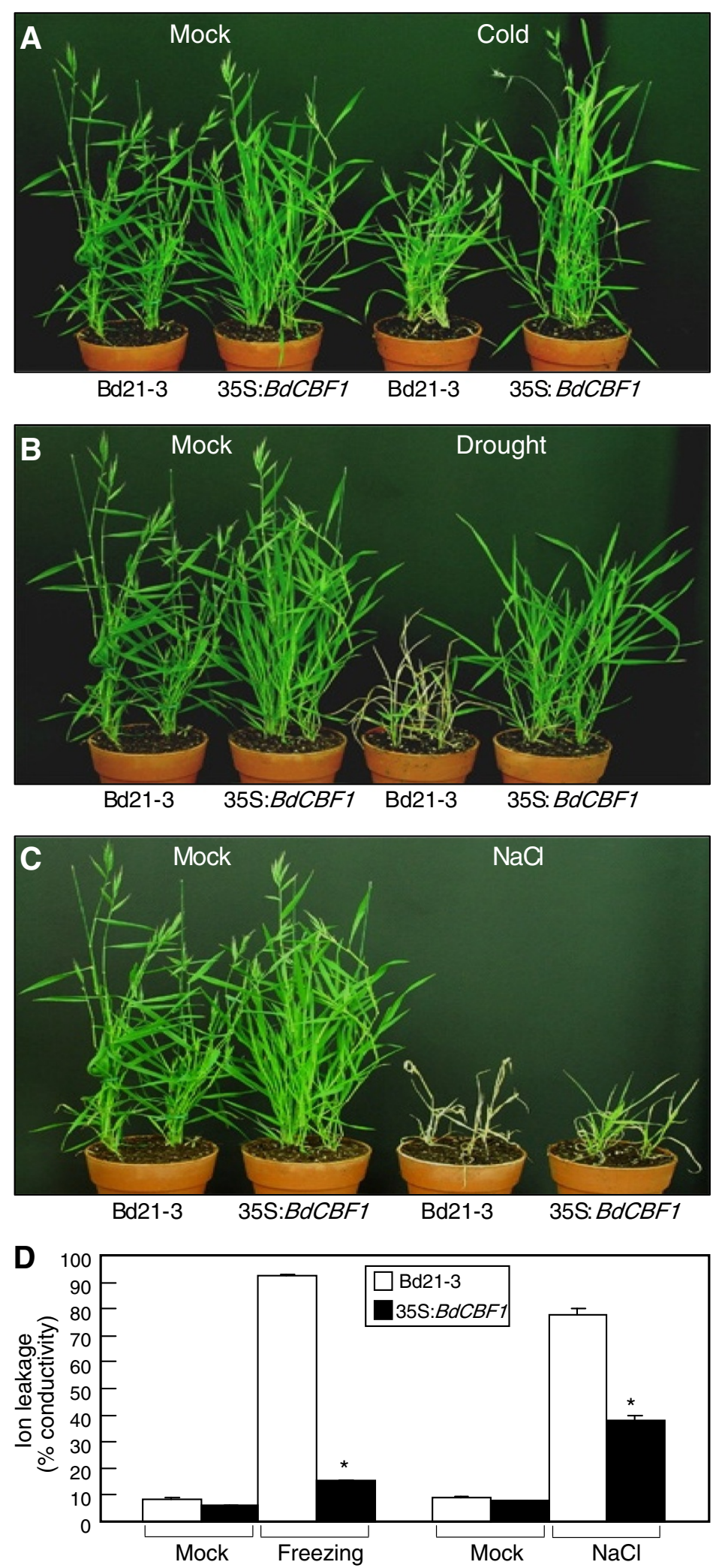

Figure 4 (See legend on next page.) 
(See figure on previous page.)

Figure 4 Stress tolerance of 35S:BdCBF1 transgenic Brachypodium plants. The BdCBF1 CDNA was transformed into Brachypodium Bd21-3 ecotype under the control of the CaMV 355 promoter. Six-week-old plants grown in soil were exposed to either cold $\left(4^{\circ} \mathrm{C}\right.$ for 6 days), drought (for 9 days without watering), or high salinity (300 mM for 3 days) conditions and allowed to recover by growing under normal growth conditions for 15 days before taking photographs. A. Cold stress tolerance. B. Drought stress tolerance. C. Salt stress tolerance. D. Electrolyte leakage assays. Two-week-old Brachypodim plants were exposed to either freezing $\left(-6^{\circ} \mathrm{C}\right)$ for $3 \mathrm{~h}$ or high salinity $(300 \mathrm{mM} \mathrm{NaCl})$ for 6 h. Rosette leaves were used for the measurements of electrolyte leakage. Five measurements were averaged and statistically treated using the Student $t$-test $\left(^{*} P<0.01\right)$. Bars indicate standard error of the mean.

$\left(-6^{\circ} \mathrm{C} / 3 \mathrm{~h}\right)$ or high salt (Figure $\left.4 \mathrm{D}\right)$. These results further support the notion that the physiological roles of the BdCBF proteins are similar to those of the CBF proteins in Arabidopsis and other plant species.

\section{Accumulation of proline and sugars in 35S:BdCBF1 transgenic Brachypodium plants}

Under abiotic stress conditions, a variety of osmolytes or compatible solutes, such as proline and soluble sugars, accumulates in plant tissues and acts as osmoprotectants that protect plants from extreme osmotic changes [36-39]. In Arabidopsis, transgenic plants overexpressing CBF3 gene are tolerant to freezing temperatures [40]. Proline and sugars accumulate to a high level in the transgenic plants under both normal and cold stress conditions. Since the 35S:BdCBF1 transgenic Brachypodium plants exhibited enhanced tolerance to abiotic stresses, we predicted that osmolytes would accumulate in the transgenic plants.

Measurements of proline contents showed that the level was higher by 30 -fold in the transgenic plants in comparison to that in the Bd21-3 control plants under normal conditions (Figure 5A). The proline levels were further elevated in the transgenic plants when they were exposed to cold and salt stresses, which is in correlation with the enhanced stress tolerance of the transgenic plants. Particularly, under cold stress conditions, whereas the proline level was elevated by 3 -fold in control plants, it was elevated by approximately 95 -fold in the transgenic plants, sustaining the role of BdCBF1 primarily in cold stress response.

We found that the levels of soluble sugars, such as glucose, raffinose, and fructose, were elevated by $3 \sim 7$ times in control plants when exposed to cold and salt stresses (Figure 5B). Notably, the sugar levels were higher in the $35 \mathrm{~S}: B d C B F 1$ transgenic plants and comparable to the levels in control plants that were exposed to freezing temperatures and salt stress. It is therefore concluded that the elevated levels of osmolytes at least in part underlie the enhanced tolerance to abiotic stresses in the 35S: $B d C B F 1$ transgenic Brachypodium plants.

\section{Abiotic stress tolerance in BdCBF1-overexpressing Arabidopsis plants}

To further characterize the functional conservation of the BdCBF transcription factors in different plant species, we produced transgenic Arabidopsis plants overexpressing the $B d C B F 1$ gene under the control of the CaMV35S promoter. Two independent transgenic lines were selected for further analysis according to the high-level expression of the transgene (Additional file 5).

The 35S:BdCBF1 transgenic Arabidopsis plants did not show any discernible phenotypic changes when grown under normal conditions (Figure 6). However, they exhibited distinct phenotypes when exposed to stress conditions. For freezing tolerance assays, two-week-old plants grown on $1 / 2 \mathrm{X}$ Murashige and Skoog-agar plates (hereafter referred to as MS-agar plates) were exposed to $-8^{\circ} \mathrm{C}$ for $5 \mathrm{~h}$ and allowed to recover at $23^{\circ} \mathrm{C}$ for 10 days. The 35S:BdCBF1 transgenic plants exhibited enhanced tolerance to freezing temperatures (Figure 6A, left panel). To access the degree of freezing tolerance, chlorophyll contents were measured using the rosette leaves. The levels of chlorophylls were higher by approximately 2 -fold in the transgenic plants in comparison to Col-0 plants transformed with vector alone (Figure 6A, right panel).

To investigate drought stress tolerance in the 35S:BdCBF1 transgenic Arabidopsis plants, two-week-old plants grown in soil were further grown without watering for 12 days, when most of the transgenic plants wilted, and rewatered for 3 days before measuring survival rates. The survival rates were significantly higher in the transgenic plants (Figure 6B): whereas the survival rates of the transgenic plants were $\sim 60 \%$, that of control plants was $12 \%$ under our assay conditions.

To examine the tolerance response of the transgenic plants under high salinity, one-week-old plants grown on MS-agar plates were transferred to fresh MS-agar plates containing $150 \mathrm{mM} \mathrm{NaCl}$ and further grown for 5 days. The 35S:BdCBF1 transgenic Arabidopsis plants were clearly more tolerant to salt stress (Figure 6C, left panel). The chlorophyll levels were approximately $70 \%$ higher in the transgenic leaves in comparison to the control leaves (Figures 6C, right panel).

Consistent with the improved tolerance to abiotic stresses in the $35 \mathrm{~S}: B d C B F 1$ transgenic Arabidopsis plants, the transcript levels of stress response genes, such as COR15A, COR414, COR6.6/KIN2, and Galactinol synthase 3 (GolS3), were significantly higher in the transgenic Arabidopsis plants (Figure 6D).

Together, our data demonstrate that the Brachypodium BdCBF transcription factors are also functional in 

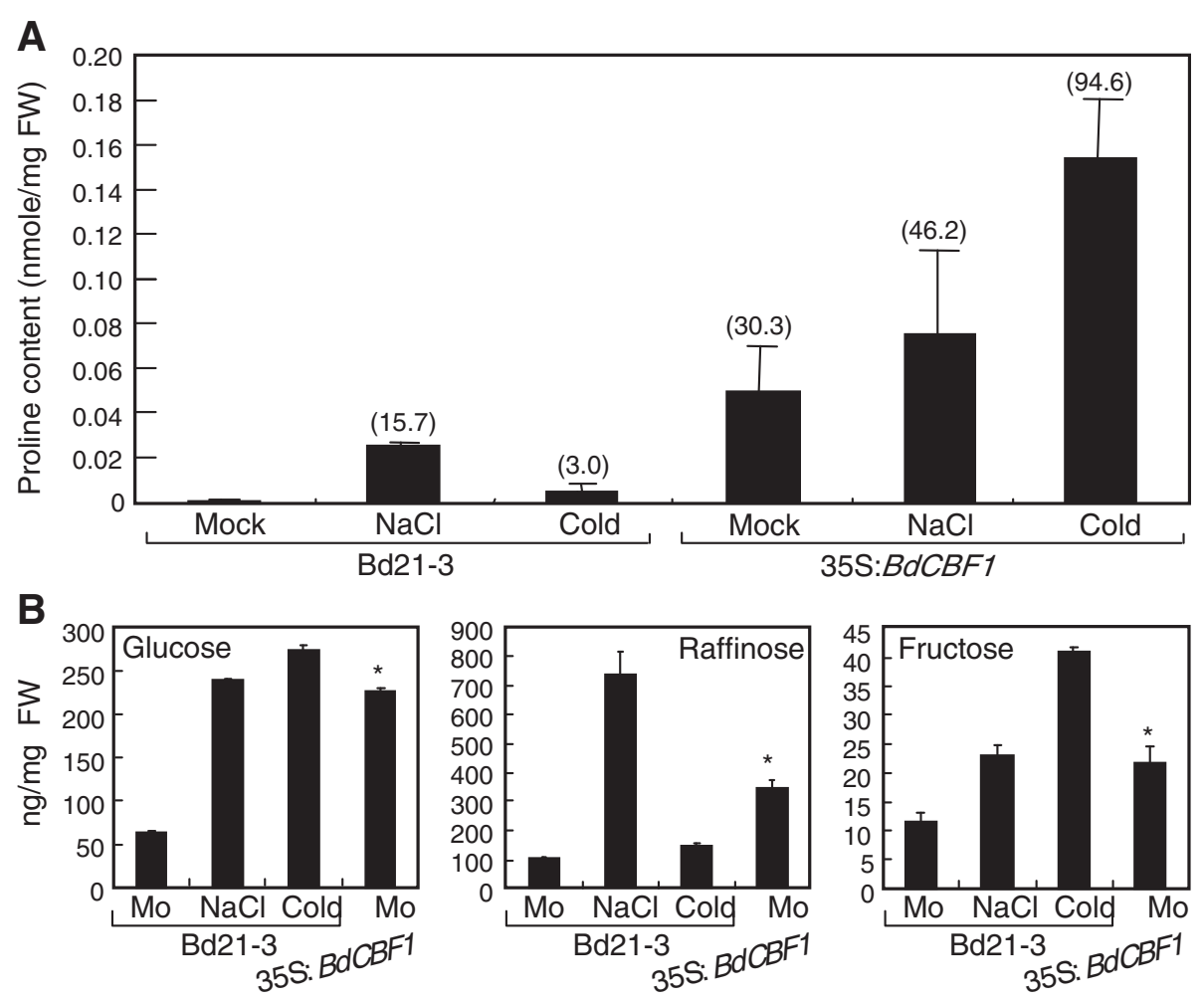

Figure 5 Contents of proline and sugars in 35S:BdCBF1 transgenic Brachypodium plants. Five measurements were averaged and statistically treated using the Student $t$-test $\left({ }^{*} P<0.01\right)$. Bars indicate standard error of the mean. A. Proline contents. Two-week-old plants grown on MS-agar plates were exposed to either $300 \mathrm{mM} \mathrm{NaCl}$ for $24 \mathrm{~h}$ or $4^{\circ} \mathrm{C}$ for $24 \mathrm{~h}$. Whole plants were used for the extraction of proline. Contents of free proline were measured by HPLC, as described previously [41]. The numbers in parentheses indicate fold changes relative to the value in the mock-treated Bd21-3 plants. Bars indicate standard error of the mean. B. Sugar contents. The plant materials described in (A) were used for the extraction of soluble sugars. Contents of individual sugars were determined by HPLC, as described previously [38]. Mo, mock.

Arabidopsis, further supporting the functional conservation of the CBF-COR cold signaling module in Brachypodium.

\section{Discussion}

Many plant species from temperate regions have the ability to acclimate to cold, nonfreezing temperatures, which is essential for plant survival at freezing temperatures. During the cold acclimation process, diverse biochemical and physiological adjustments occur in plant cells. The cold-responsive cellular events include modifications of lipid composition in the cellular membranes and accumulation of osmoprotectants, including antifreeze proteins, proline, and sugars [42-45].

Cold acclimation is associated with extensive changes in the transcriptome, among which changes in the expression patterns of transcription factor genes are most prevailing $[5,6]$. In Arabidopsis, a central cold signaling pathway includes the $\mathrm{CBF}$ transcription factors that directly regulate an array of COR genes through the supposed ICE1-CBFCOR regulon [46-48]. Consequently, genes constituting the cold signaling pathway and underlined molecular mechanisms have been comprehensively studied in Arabidopsis $[2,4-6,11]$.
The $C B F$ genes have been functionally characterized using gene-deficient mutants and transgenic plants overexpressing them in several plant species [7-9,12,16]. Numerous $C B F$ gene homologues have been identified through genomic sequence analysis in both monocots and dicots $[17,19,49]$. Accumulating evidence in recent years indicate that the CBF signaling pathways are conserved in diverse plant species.

The Brachypodium genome contains more than a hundred of AP2 domain-containing proteins, among which 14 members have been identified as CBF3 homologues by BLAST searches and phylogenetic analyses [30]. Through similar approaches, we identified 15 putative BdCBF proteins that are classified into 3 clades. Clades I and II contain one and two BdCBF members, respectively. Clade III contains 12 BdCBF members, similar to what have been identified previously [30]. Based on the phylogenetic analyses, we selected one member that is cold responsive from each clade, and the selected BdCBF proteins (BdCBF1-3) were functionally studied in cold response and other abiotic stress responses using transgenic Brachypodium and Arabidopsis plants.

The predicted amino acid sequences of the BdCBF1 proteins are highly homologous to those in other plant 


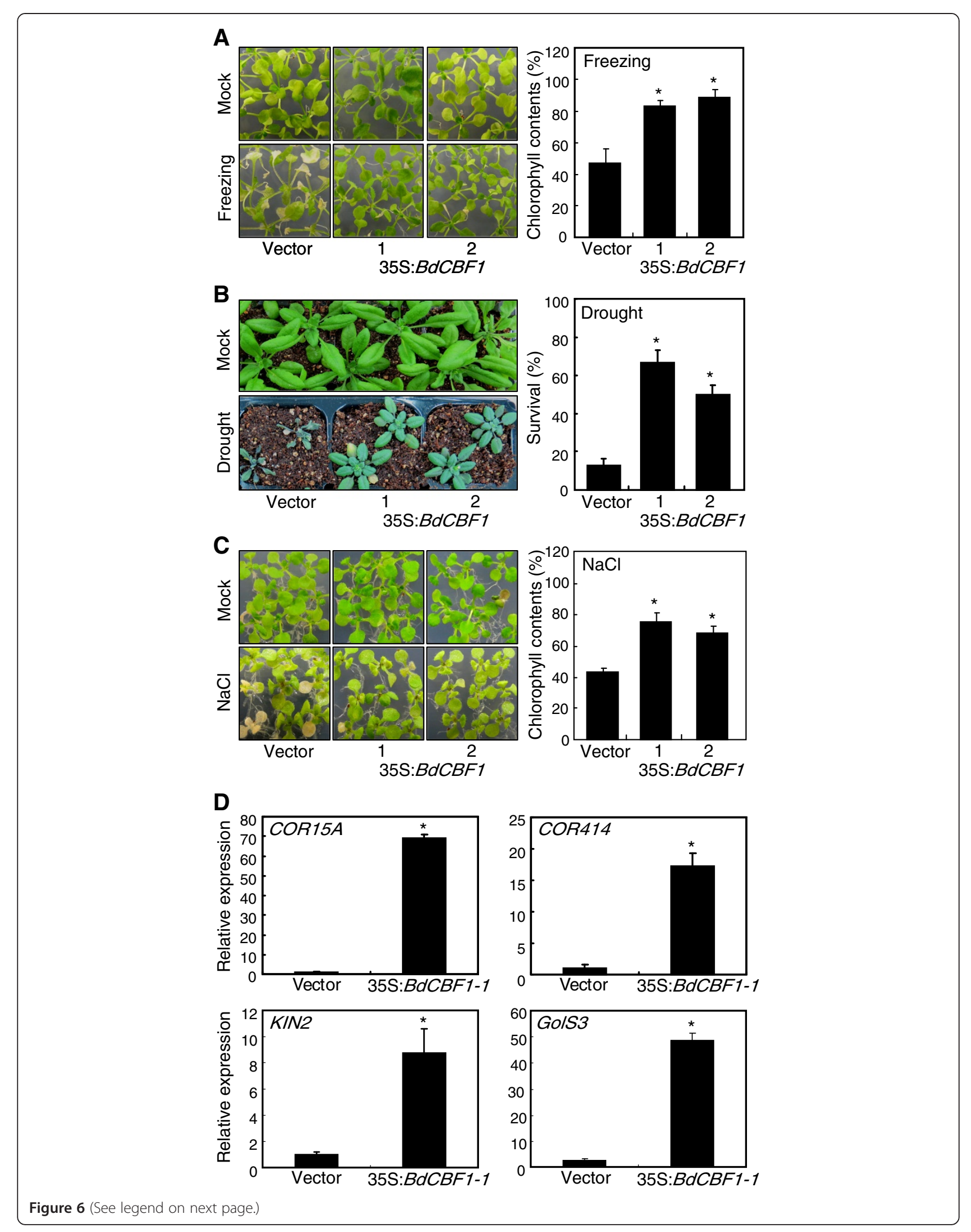




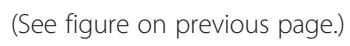

species, particularly to those in wheat, barley, and rice. The AP2 DNA-binding domains of the BdCBF proteins have the highest sequence identity to those in these plant species among others. In Arabidopsis, CBF1, CBF2 and CBF3 bind to the CRT/DRE elements of COR genes. We found that the BdCBF1 protein binds specifically to the CRT motif within the COR gene promoters from barley and Arabidopsis, sustaining the functional conservation of BdCBF1, and perhaps BdCBF2 and BdCBF3 as well, in Brachypodium.

Expression patterns of the $B d C B F$ genes under abiotic stress conditions were quite similar to what observed in Arabidopsis [7,8]. The BdCBF1, BdCBF2 and BdCBF3 genes were induced by cold, high salinity, and drought but with some degree of variations. One distinction was that the $B d C B F$ genes were not influenced by $A B A$. It has been reported that $A B A$ induces the transcription of $C B F$ genes, leading to subsequent induction of $C O R$ genes in Arabidopsis [50]. Although further studies are required to confirm the relationship between ABA signaling and $B d C B F$ gene expression, molecular mechanisms underlying the stress induction of the $B d C B F$ genes would be somewhat different in different plant species. This distinction may be related with recent findings, in which it has been observed that the CBF proteins have both common and distinct roles in different plant species [17-23].

The correlation between proline accumulation and induction of low temperature tolerance has been demonstrated in maize [51]. The roles of proline and soluble sugars as osmoprotectants in low temperature tolerance have also been demonstrated in Arabidopsis and rice plants overexpressing CBF3 gene [40]. The GolS3 gene, which encodes galactinol synthase catalyzing the first step of the biosynthesis of raffinose family oligosaccharides [52], was induced in the CBF3-overexpressing transgenic Arabidopsis plants [39]. We found that the levels of proline and soluble sugars were significantly elevated in the 35S:BdCBF transgenic Brachypodium plants that exhibit enhanced stress tolerance. Abiotic stress tolerance was also improved in the transgenic Arabidopsis plants overexpressing the $B d C B F$ genes, and $C O R$ genes, such as COR15A, COR414, KIN2, and GolS3 that are directly regulated by CBF transcription factors, were markedly upregulated in the transgenic Arabidopsis plants [53]. Together with the sequence similarities and phylogenetic relationships of the BdCBF1, BdCBF2, and BdCBF3 proteins to the CBF proteins in Arabidopsis and monocot plants, our data on the functional assays strongly support that the CBF proteins and associated CBF-mediated signaling pathways are conserved in Brachypodium.

Improvement of stress tolerance is a potential target of genetic engineering in bioenergy grass, such as switchgrass and Miscanthus $[29,54]$. Based on the genetic similarity between the grass species and Brachypodium, it is envisioned that the BdCBF-COR regulon would readily be applicable to the bioenergy grass species as efficient transformation systems are to be established in near future.

\section{Conclusions}

We identified three $C B F$ gene homologues ( $B d C B F 1$, $B d C B F 2$, and $B d C B F 3$ ) encoding potential transcription factors in the Brachypodium distachyon genome and functionally characterized the BdCBF transcription factors using $B d C B F$-overexpressing transgenic Brachypodium and Arabidopsis plants that exhibit enhanced tolerance to cold temperatures and drought and salt stresses. Proline and soluble sugars accumulated to high levels in the transgenic Brachypodium plants. A set of COR genes were upregulated in the transgenic Arabidopsis plants. It is therefore concluded that the CBF-mediated cold signaling pathway is conserved in Brachypodium.

\section{Methods}

\section{Plant materials and growth conditions}

Brachypodium distachyon ecotype $\mathrm{Bd} 21-3$, which is a community standard diploid inbred line, was used in all experiments. Brachypodium plants were grown in a controlled growth chamber with relative humidity of $60 \%$ under long day conditions (20-h light/4-h dark). Growth conditions were $24^{\circ} \mathrm{C}$ during the day and $18^{\circ} \mathrm{C}$ at night with white light illumination provided by FLR40D/A fluorescent tubes $\left(150 \mu \mathrm{mol}\right.$ photons $/ \mathrm{m}^{2} \mathrm{~s}$, Osram, Seoul, Korea).

The Arabidopsis ecotype Columbia (Col-0) was used for $B d C B F$ gene transformation. Arabidopsis plants were grown in a controlled culture room at $22^{\circ} \mathrm{C}$ with relative humidity of $55 \%$ under long day conditions (16-h light/8-h dark) with white light illumination provided by fluorescent FLR40D/A tubes $\left(120 \mu \mathrm{mol}\right.$ photons $/ \mathrm{m}^{2} \mathrm{~s}$, Osram). 


\section{Plant transformation}

To produce transgenic Brachypodium and Arabidopsis plants overexpressing $B d C B F 1$ cDNA, the $B d C B F 1$ cDNA was amplified from a Brachypodium cDNA pool and subcloned into the binary pJJ461 vector under the control of the CaMV $35 \mathrm{~S}$ promoter. Brachypodium transformation was performed according to the Agrobacterium tumefaciens-mediated method using compact embryogenic calli derived from immature embryos [55]. A. tumefaciensmediated Arabidopsis transformation was performed according to a modified floral dip method [56].

\section{Analysis of gene transcript levels}

Total RNA was extracted from plant materials using the RNeasy Plant Mini Kit (Qiagen, Valencia, CA) according to the manufacturer's procedure. Before RT-PCR and qRTPCR, total RNA samples were pretreated with a RNase-free DNase I to eliminate contaminating genomic DNA. Primary cDNA was synthesized from approximately $2 \mu \mathrm{g}$ of total RNA using the MMLV first-strand synthesis system (Promega, Madison, WI).

One $\mu$ l of the primary cDNA synthesis reaction mixture $(20 \mu \mathrm{l})$ was taken for subsequent PCR amplification. RTPCR runs consisted of 15-35 cycles, depending on the linear range of PCR amplification for individual genes. Each PCR cycle included incubations at $94^{\circ} \mathrm{C}$ for $0.5 \mathrm{~min}$, at $55^{\circ} \mathrm{C}$ for $0.5 \mathrm{~min}$ and at $72^{\circ} \mathrm{C}$ for $3 \mathrm{~min}$. One additional cycle at $72^{\circ} \mathrm{C}$ for $7 \mathrm{~min}$ was included after the last cycle to allow completion of incomplete polymerizations.

qRT-PCR was performed in 96-well blocks with the Applied Biosystems 7500 Real-Time PCR System (Foster City, CA) using the SYBR Green I master mix in a volume of $20 \mu \mathrm{l}$. The PCR primers were designed using the Primer Express software installed in the system and listed in (Additional file 6). The two-step thermal cycling profile and processing of qRT-PCR data were performed as described previously [57]. For the accurate measurements of gene transcript levels, biological triplicates were averaged and statistically treated using the Student $t$-test.

\section{BLAST searches and phylogenetic analyses}

To identify putative CBF homologues in the Brachypodium genome, the BLAST search tool was employed (http:// blast.ncbi.nlm.nih.gov/Blast.cgi). BLAST searches were performed using the Arabidopsis CBF1, CBF2, and CBF3 proteins as baits. Nineteen $\mathrm{CBF}$ homologues having higher than $50 \%$ amino acid sequence similarities throughout the full sequences were selected for further studies. Phylogenetic analyses were performed on the 19 Brachypodium CBF homologues using the MEGA5 software, as described previously [32], and 15 members of them were designated BdCBF proteins.

To investigate the phylogenetic relationship between the BdCBF1, BdCBF2, and BdCBF3 proteins and those from other monocots, amino acid sequences of putative CBF proteins of Hordeum vulgare, Oryza sativa, Sorghum bicolor, Secale cereale, Triticum aestivum, and Zea mays were obtained from the Plant Genome Database (PlantGDB, http://www.plantgdb.org/) and National Center for Biotechnology Information (NCBI, http:// www.ncbi.nlm.nih.gov/).

\section{Abiotic stress treatments}

To examine the effects of abiotic stresses on $B d C B F$ gene expression in Brachypodium, two-week-old plants grown on MS-agar plates were transferred to MS liquid cultures supplemented with either $400 \mathrm{mM}$ mannitol, $300 \mathrm{mM} \mathrm{NaCl}$, or $100 \mu \mathrm{M} \mathrm{ABA}$, and incubated for various time durations with gentle shaking. For cold treatments, plants were exposed to $4^{\circ} \mathrm{C}$ for various time durations before harvesting plant materials.

To examine the effects of abiotic stresses on Brachypodium growth, six-week-old plants grown in soil were used. For cold treatments, plants were exposed to $4^{\circ} \mathrm{C}$ for 6 days and transferred to normal growth conditions for 15 days. For drought treatments, plants were grown for 9 days without watering, when symptoms of wilting are evident in most of 35S:BdCBF1 transgenic Brachypodium plants, and transferred to normal growth conditions with rewatering for 15 days. For salt stress treatments, plants were watered with $300 \mathrm{mM} \mathrm{NaCl}$ solution for 3 days, and the soil was extensively washed with deionized water. The salttreated plants were further grown under normal growth conditions for 15 days.

For the assays on freezing tolerance in Arabidopsis, one-week-old plants grown on MS-agar plates were exposed to $-8^{\circ} \mathrm{C}$ for $5 \mathrm{~h}$ and allowed to recover at $23^{\circ} \mathrm{C}$ for 10 days. For the assays on drought tolerance in Arabidopsis, two-week-old plants grown in soil were subsequently grown for 12 days without watering until symptoms of wilting are visible in most of $35 \mathrm{~S}: B d C B F 1$ transgenic Arabidopsis plants. Survival rates were calculated 3 days after rewatering. For the assays on salt tolerance in Arabidopsis, one-week-old plants grown on MS-agar plates were transferred to MS-agar plates supplemented with $150 \mathrm{mM} \mathrm{NaCl}$ and further grown for 5 days.

The survival rates were calculated by counting 30-35 plants for each plant genotype and statistically treated using the Student $t$-test.

\section{Subcellular localization of BdCBF1}

The GFP-coding sequence was fused in-frame to the 3' end of $B d C B F 1$ cDNA sequence, and the gene fusion was expressed transiently in Brachypodium protoplasts, as described previously [34]. After incubation for $16 \mathrm{~h}$ at room temperature in complete darkness, the protoplasts were observed using the Multi-photon Confocal Laser Scanning microscope (Carl Zeiss, Jena, Germany). 


\section{Transcriptional activation activity assays}

Transient expression assays in Brachypodium protoplasts were employed to examine the transcriptional activation activity of BdCBF1. The reporter and effector plasmids were constructed as follows. The reporter plasmid contained four copies of the GAL4 upstream activation sequence and the GUS reporter gene. To construct the p35S:BdCBF1 effector plasmid, $B d C B F 1$ cDNA was fused to the GAL4 DB-coding sequence and inserted into an expression vector containing the CaMV $35 \mathrm{~S}$ promoter. The reporter and effector plasmids were cotransformed into Brachypodium protoplasts by a polyethylene glycol-mediated transformation method [34]. GUS activity was measured by the fluorometric method, as described previously [34]. A CaMV 35S promoter-luciferase construct was also cotransformed as internal control. The luciferase assay was performed using the Luciferase Assay System (Promega). Five measurements were averaged and statistically treated using the Student $t$-test $\left({ }^{*} \mathrm{P}<0.01\right)$ for each assay.

\section{EMSA assays}

The BdCBF1 cDNA was subcloned into the pET-28a $E$. coli expression vector having a His-coding sequence (Novagen, Darmstadt, Germany). The BdCBF1-His fusion was expressed in BL21(DE3)pLysS E. coli cells and purified using Ni-NTA agarose beads (Qiagen, Venlo, Netherlands). DNA fragments were end-labeled with $\left[\gamma^{-}{ }^{32} \mathrm{P}\right] \mathrm{dATP}$ using T4 polynucleotide kinase. Labeled probes were incubated with $\sim 0.5 \mu \mathrm{g}$ of purified recombinant BdCBF1-His proteins for $30 \mathrm{~min}$ at $25^{\circ} \mathrm{C}$ in binding buffer $(10 \mathrm{mM}$ Tris-Cl, pH7.6, $50 \mathrm{mM} \mathrm{NaCl}, 1 \mathrm{mM}$ EDTA, 5 mM DTT, and 5\% glycerol). The reaction mixtures were electrophoresed on $6 \%$ native PAGE gels. The gels were dried on Whatman 3MM paper and exposed to X-ray films.

\section{Measurements of proline and sugar contents}

For the measurement of endogenous contents of proline and sugars in Brachypodium, two-week-old plants grown on MS-agar plates were exposed to $300 \mathrm{mM} \mathrm{NaCl}$ for $24 \mathrm{~h}$ or $4^{\circ} \mathrm{C}$ for $24 \mathrm{~h}$. Whole plants were quick-frozen in liquid nitrogen and homogenized. The homogenate was extracted in $80 \%$ methanol and boiled for $10 \mathrm{~min}$. The contents of proline and soluble sugars were quantified by high performance liquid chromatography at the National Instrumentation Center for Environmental Management (NICEM), College of Agriculture and Life Sciences, Seoul National University, Seoul, Korea. Five measurements were averaged and statistically treated using the Student $t$-test for each assay.

\section{Electrolyte leakage assays}

To evaluate the degree of cellular injury by freezing temperatures and high salinity in Brachypodium, the percentage of electrolyte leakage was measured. Two-week-old plants grown on MS-agar plates were either exposed to $-6^{\circ} \mathrm{C}$ for $3 \mathrm{~h}$ or soaked in MS liquid medium containing $300 \mathrm{mM} \mathrm{NaCl}$ for $6 \mathrm{~h}$. The aerial plant parts were briefly washed with deionized water and soaked in deionized water for $12 \mathrm{~h}$ in complete darkness before measuring sample conductivity using the Orion 5-star conductivity meter (Thermo, Beverly, MA). The plant materials were then boiled in the same solution for $5 \mathrm{~min}$, and total conductivity of the solution was measured. Electrolyte leakage is represented by the relative conductivity that is calculated by dividing sample conductivity by total conductivity. Five measurements were averaged and statistically treated using the Student $t$-test for each assay.

\section{Measurements of chlorophyll contents}

Measurements of chlorophyll contents in Arabidopsis were performed as described previously [58]. Chlorophylls were extracted with $\mathrm{N}, \mathrm{N}$-dimethylformamide from the rosette leaves, and the extracted solution was incubated at $4{ }^{\circ} \mathrm{C}$ for $2 \mathrm{~h}$ in complete darkness. Chlorophyll contents were assayed by measuring absorbance at $652 \mathrm{~nm}, 665 \mathrm{~nm}$, and $750 \mathrm{~nm}$ using a diode array spectrophotometer (WPA Biowave, Cambridge, UK). Five measurements were averaged and statistically treated using the Student $t$-test for each assay.

\section{Additional files}

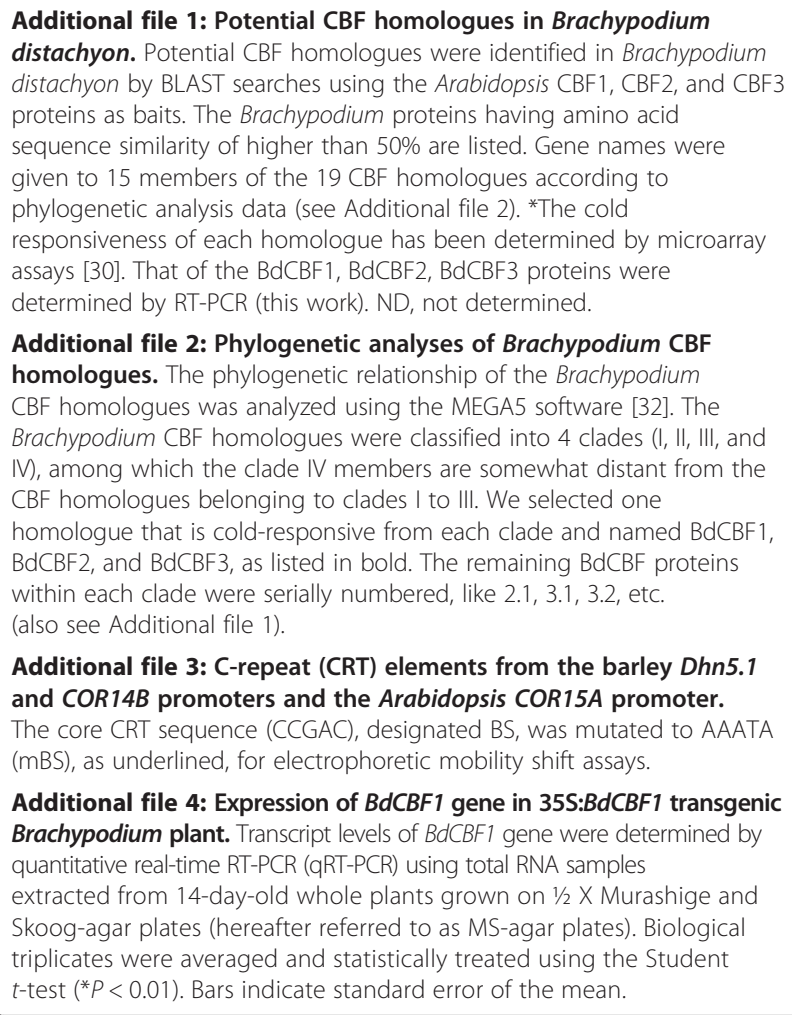

Additional file 2: Phylogenetic analyses of Brachypodium CBF homologues. The phylogenetic relationship of the Brachypodium CBF homologues was analyzed using the MEGA5 software [32]. The Brachypodium CBF homologues were classified into 4 clades (I, II, III, and IV), among which the clade IV members are somewhat distant from the CBF homologues belonging to clades I to III. We selected one homologue that is cold-responsive from each clade and named BdCBF1, $\mathrm{BdCBF} 2$, and $\mathrm{BdCBF} 3$, as listed in bold. The remaining BdCBF proteins within each clade were serially numbered, like 2.1, 3.1, 3.2, etc. (also see Additional file 1).

Additional file 3: C-repeat (CRT) elements from the barley Dhn5.1 and COR14B promoters and the Arabidopsis COR15A promoter. The core CRT sequence (CCGAC), designated BS, was mutated to AAATA (mBS), as underlined, for electrophoretic mobility shift assays.

Additional file 4: Expression of $B d C B F 1$ gene in 35S:BdCBF1 transgenic Brachypodium plant. Transcript levels of $B d C B F 1$ gene were determined by quantitative real-time RT-PCR (qRT-PCR) using total RNA samples extracted from 14-day-old whole plants grown on $1 / 2 \times$ Murashige and Skoog-agar plates (hereafter referred to as MS-agar plates). Biological triplicates were averaged and statistically treated using the Student t-test $\left({ }^{*} P<0.01\right)$. Bars indicate standard error of the mean. 
Additional file 5: Expression of $B d C B F 1$ gene in 35S:BdCBF1 transgenic Arabidopsis plants. Transcript levels of $B d C B F 1$ gene were determined by RT-PCR using total RNA samples extracted from 10-day-old whole plants grown on MS-agar Plates. A tubulin gene (TUB) was used as RNA quality control.

Additional file 6: Primers used in qRT-PCR and RT-PCR. F, forward primer; $R$, reverse primer.

\section{Competing interests}

The authors declare that they have no competing interests.

\section{Authors' contributions}

CMP and SYH conceptualized the project and analyzed the data. CMP, JYR, and SL wrote the manuscript. SYH, JYR, SHJ, and JCW carried out the molecular and biochemical assays on Brachypodium distachyon. SL and JYR transformed the BdCBF1 gene into Arabidopsis thaliana and analyzed the stress response of the transgenic plants. All authors discussed the results and approved the final form of the manuscript.

\section{Acknowledgements}

This work was supported by the Leaping Research (20120005600) and Global Research Lab (2012055546) Programs provided by the National Research Foundation of Korea and the Next-Generation BioGreen 21 Program (Plant Molecular Breeding Center No. 201203013055290010200) provided by the Rural Development Administration of Korea. It was also supported in part by the Human Frontier Science Program (RGP0002/2012).

\section{Author details}

'Department of Chemistry, Seoul National University, Seoul 151-742, Korea. ${ }^{2}$ Department of Biological Science, Mokpo National University, Jeonnam 534-729, Korea. ${ }^{3}$ Plant Genomics and Breeding Institute, Seoul National University, Seoul 151-742, Korea.

Received: 18 November 2013 Accepted: 8 January 2014 Published: 9 January 2014

\section{References}

1. Niklas KJ: Functional adaptation and phenotypic plasticity at the cellular and whole plant level. J Biosci 2009, 34:613-620

2. Chinnusamy V, Zhu J, Zhu JK: Cold stress regulation of gene expression in plants. Trends Plant Sci 2007, 12:444-451.

3. Pino MT, Skinner JS, Jeknic Z, Hayes PM, Soeldner AH, Thomashow MF, Chen TH: Ectopic AtCBF1 over-expression enhances freezing tolerance and induces cold acclimation-associated physiological modifications in potato. Plant Cell Environ 2008, 31:393-406.

4. Yamaguchi-Shinozaki K, Shinozaki K: Transcriptional regulatory networks in cellular responses and tolerance to dehydration and cold stresses. Annu Rev Plant Biol 2006, 57:781-803.

5. Shinozaki K, Yamaguchi-Shinozaki K, Seki M: Regulatory network of gene expression in the drought and cold stress responses. Curr Opin Plant Biol 2003, 6:410-417.

6. Thomashow MF: Plant cold acclimation: freezing tolerance genes and regulatory mechanisms. Annu Rev Plant Physiol Plant Mol Biol 1999, 50:571-599.

7. Stockinger EJ, Gilmour SJ, Thomashow MF: Arabidopsis thaliana CBF1 encodes an AP2 domain-containing transcriptional activator that binds to the C-repeat/DRE, a cis-acting DNA regulatory element that stimulates transcription in response to low temperature and water deficit. Proc Natl Acad Sci U S A 1997, 94:1035-1040.

8. Gilmour SJ, Zarka DG, Stockinger EJ, Salazar MP, Houghton JM, Thomashow MF: Low temperature regulation of the Arabidopsis CBF family of AP2 transcriptional activators as an early step in cold-induced COR gene expression. Plant J 1998, 16:433-442.

9. Liu Q, Kasuga M, Sakuma Y, Abe H, Miura S, Yamaguchi-Shinozaki K, Shinozaki K: Two transcription factors, DREB1 and DREB2, with an EREBP/AP2 DNA binding domain separate two cellular signal transduction pathways in drought- and low temperature-responsive gene expression, respectively, in Arabidopsis. Plant Cell 1998, 10:1391-1406.

10. Haake V, Cook D, Riechmann JL, Pineda O, Thomashow MF, Zhang JZ: Transcription factor CBF4 is a regulator of drought adaptation in Arabidopsis. Plant Physiol 2002, 130:639-648.
11. Chinnusamy V, Ohta M, Kanrar S, Lee BH, Hong X, Agarwal M, Zhu JK: ICE1: a regulator of cold induced transcriptome and freezing tolerance in Arabidopsis. Genes Dev 2003, 17:1043-1054

12. Jaglo-Ottosen KR, Gilmour SJ, Zarka DG, Schabenberger O, Thomashow MF: Arabidopsis CBF1 overexpression induces COR genes and enhances freezing tolerance. Science 1998, 280:104-106.

13. Kasuga M, Liu Q, Miura S, Yamaguchi-Shinozaki K, Shinozaki K: Improving plant drought, salt, and freezing tolerance by gene transfer of a single stress inducible transcription factor. Nat Biotechnol 1999, 17:287-291.

14. Dong $\mathrm{CH}$, Agarwal $\mathrm{M}$, Zhang $Y$, Xie $\mathrm{Q}$, Zhu JK: The negative regulator of plant cold responses, HOS1, is a RING E3 ligase that mediates the ubiquitination and degradation of ICE1. Proc Natl Acad Sci U S A 2006, 103:8281-8286.

15. Agarwal $M$, Hao $Y$, Kapoor A, Dong CH, Fujii H, Zheng X, Zhu JK: A R2R3 type MYB transcription factor is involved in the cold regulation of $C B F$ genes and in acquired freezing tolerance. J Biol Chem 2006, 281:37636-37645.

16. Novillo F, Alonso JM, Ecker JR, Salinas J: CBF2/DREB1C is a negative regulator of $C B F 1 / D R E B 1 B$ and $C B F 3 / D R E B 1 A$ expression and plays a central role in stress tolerance in Arabidopsis. Proc Natl Acad Sci U S A 2004, 101:3985-3990.

17. Jaglo KR, Kleff S, Amundsen KL, Zhang X, Haake V, Zhang JZ, Deits T, Thomashow MF: Components of the Arabidopsis C-repeat/dehydration-responsive element binding factor cold-response pathway are conserved in Brassica napus and other plant species. Plant Physiol 2001, 127:910-917.

18. Dubouzet JG, Sakuma Y, Ito Y, Kasuga M, Dubouzet EG, Miura S, Seki M, Shinozaki K, Yamaguchi-Shinozaki K: OsDREB genes in rice, Oryza sativa L., encode transcription activators that function in drought-, high salt- and cold-responsive gene expression. Plant J 2003, 33:751-763.

19. Choi DW, Rodriguez EM, Close TJ: Barley Cbf3 gene identification, expression pattern, and map location. Plant Physiol 2002, 129:1781-1787.

20. Vágúffalvi A, Galiba G, Cattivelli L, Dubcovsky J: The cold-regulated transcriptional activator $\mathrm{Cbf} 3$ is linked to the frost-tolerance locus Fr-A2 on wheat chromosome 5A. Mol Genet Genomics 2003, 269:60-67.

21. Skinner JS, Zitzewitz J, Szucs P, Marquez-Cedillo L, Filichkin T, Amundsen K, Stockinger EJ, Thomashow MF: Structural, functional, and phylogenetic characterization of a large CBF gene family in barley. Plant Mol Biol 2005, 59:533-551

22. Jeknić Z, Pillman KA, Dhillon T, Skinner JS, Veisz O, Cuesta-Marcos A, Hayes PM, Jacobs AK, Chen TH, Stockinger EJ: Hv-CBF2A overexpression in barley accelerates $C O R$ gene transcript accumulation and acquisition of freezing tolerance during cold acclimation. Plant Mol Biol 2014, 84:67-82.

23. Xue G: The DNA-binding activity of an AP2 transcriptional activator $\mathrm{HvCBF}$ involved in regulation of low-temperature responsive genes in barley is modulated by temperature. Plant J 2003, 33:373-383.

24. Brkljacic J, Grotewold E, Scholl R, Mockler T, Garvin DF, Vain P, Brutnell T, Sibout R, Bevan M, Budak H, Caicedo AL, Gao C, Gu Y, Hazen SP, Holt BF 3rd, Hong SY, Jordan M, Manzaneda AJ, Mitchell-Olds T, Mochida K, Mur LA, Park CM, Sedbrook J, Watt M, Zheng SJ, Vogel JP: Brachypodium as a model for the grasses: today and the future. Plant Physiol 2011, 157:3-13.

25. Draper J, Mur LA, Jenkins G, Ghosh-Biswas GC, Bablak P, Hasterok R, Routledge AP: Brachypodium distachyon. A new model system for functional genomics in grasses. Plant Physiol 2001, 127:1539-1555.

26. Garvin D, Gu Y, Hasterok R, Hazen SP, Jenkins G, Mokler TC, Mur LA, Vogel $J P$ : Development of genetic and genomic research resources for Brachypodium distachyon, a new model system for grass crop research. Plant Genome 2008, 48:69-84.

27. Bevan MW, Garvin DF, Vogel JP: Brachypodium distachyon genomics for sustainable food and fuel production. Curr Opin Biotechnol 2010, 21:211-217

28. Matos DA, Whitney IP, Harrington MJ, Hazen SP: Cell walls and the developmental anatomy of the Brachypodium distachyon stem internode. PLoS One 2013, 8:e80640.

29. Yuan JS, Tiller KH, Al-Ahmad H, Stewart NR, Stewart CN Jr: Plants to power: bioenergy to fuel the future. Trends Plant Sci 2008, 13:165-171.

30. Li C, Rudi H, Stockinger E, Cheng H, Cao M, Fox S, Mockler T, Westereng B, Fjellheim S, Rognli OA, Sandve SR: Comparative analyses reveal potential uses of Brachypodium distachyon as a model for cold stress responses in temperate grasses. BMC Plant Biol 2012, 12:65.

31. Badawi M, Danyluk J, Boucho B, Houde M, Sarhan F: The CBF gene family in hexaploid wheat and its relationship to the phylogenetic complexity of cereal CBFs. Mol Genet Genomics 2007, 277:533-554 
32. Tamura K, Peterson D, Peterson N, Stecher G, Nei M, Kumar S: MEGA5: Molecular evolutionary genetics analysis using maximum likelihood, evolutionary distance, and maximum parsimony methods. Mol Biol Evol 2011, 28:2731-2739.

33. Tiwari SB, Hagen G, Guilfoyle T: The roles of auxin response factor domains in auxin-responsive transcription. Plant Cell 2003, 15:533-543.

34. Hong SY, Seo PJ, Cho SH, Park CM: Preparation of leaf mesophyll protoplasts for transient gene expression in Brachypodium distachyon. J Plant Biol 2012, 55:390-397.

35. Hirayama T, Shinozaki K: Perception and transduction of abscisic acid signals: keys to the function of the versatile plant hormone $A B A$. Trends Plant Sci 2007, 12:343-351.

36. Ishitani M, Majumder AL, Bornhouser A, Michalowski CB, Jensen RG, Bohnert $\mathrm{HJ}$ : Coordinate transcriptional induction of myo-inositol metabolism during environmental stress. Plant J 1996, 9:537-548.

37. Igarashi Y, Yoshiba Y, Sanada Y, Yamaguchi-Shinozaki K, Wada K, Shinozaki $\mathrm{K}$ : Characterization of the gene for delta1-pyrroline-5-carboxylate synthetase and correlation between the expression of the gene and salt tolerance in Oryza sativa L. Plant Mol Biol 1997, 33:857-865.

38. Wanner LA, Junttila O: Cold-induced freezing tolerance in Arabidopsis. Plant Physiol 1999, 120:391-399.

39. Taji T, Ohsumi C, luchi S, Seki M, Kasuga M, Kobayashi M, Yamaguchi-Shinozaki K, Shinozaki K: Important roles of drought- and cold-inducible genes for galactinol synthase in stress tolerance in Arabidopsis thaliana. Plant J 2002, 29:417-426.

40. Gilmour SJ, Sebolt AM, Salazar MP, Everard JD, Thomashow MF: Overexpression of the Arabidopsis CBF3 transcriptional activator mimics multiple biochemical changes associated with cold acclimation. Plant Physiol 2000, 124:1854-1865.

41. Nanjo T, Kobayashi M, Yoshiba Y, Kakubari Y, Yamaguchi-Shinozaki K, Shinozaki $\mathrm{K}$ : Antisense suppression of proline degradation improves tolerance to freezing and salinity in Arabidopsis thaliana. FEBS Lett 1999, 461:205-210.

42. Rudolph AS, Crowe JH, Crowe LM: Effects of three stabilizing agents - proline, betaine, and trehalose on membrane phospholipids. Arch Biochem Biophys 1986, 245:134-143.

43. Nishida I, Murata N: Chilling sensitivity in plants and cyanobacteria: the crucial contribution of membrane lipid. Annu Rev Plant Physiol Plant Mol Biol 1996, 47:541-568.

44. Uemura M, Warren G, Steponkus PL: Freezing sensitivity in the sfr4 mutant of Arabidopsis is due to low sugar content and is manifested by loss of osmotic responsiveness. Plant Physiol 2003, 131:1800-1807.

45. Kaplan F, Guy CL: $\beta$-Amylase induction and the protective role of maltose during temperature shock. Plant Physiol 2004, 135:1674-1684.

46. Lee BH, Henderson DA, Zhu JK: The Arabidopsis cold responsive transcriptome and its regulation by ICE1. Plant Cell 2005, 17:3155-3175.

47. Benedict C, Geisler M, Trygg J, Huner N, Hurry V: Consensus by democracy. Using meta-analyses of microarray and genomic data to model the cold acclimation signaling pathway in Arabidopsis. Plant Physiol 2006 141:1219-1232.

48. Chinnusamy V, Zhu JK, Sunkar R: Gene regulation during cold stress acclimation in plants. Methods Mol Biol 2010, 639:39-55.

49. Xue GP: Characterization of the DNA-binding profile of barley HvCBF1 using an enzymatic method for rapid, quantitative and high-throughput analysis of the DNA binding activity. Nucleic Acids Res 2002, 30:e77.

50. Knight H, Zarka DG, Okamoto H, Thomashow MF, Knight MR: Abscisic acid induces CBF gene transcription and subsequent induction of cold-regulated genes via the CRT promoter element. Plant Physiol 2004, 135:1710-1717.

51. Xin Z, Li PH: Relationship between proline and abscisic acid in the induction of chilling tolerance in maize suspension-cultured cells. Plant Physiol 1993, 103:607-613.

52. Dey PM, Dixon RA: Biochemistry of storage carbohydrates in green plants. New York: Academic Press; 1985:53-130.

53. Sakuma Y, Maruyama K, Osakabe Y, Qin F, Seki M, Shinozaki K, Yamaguchi-Shinozaki K: Functional analysis of an Arabidopsis transcription factor, DREB2A, involved in drought-responsive gene expression. Plant Cell 2006, 18:1292-1309.

54. Sticklen MB: Plant genetic engineering for biofuel production: towards affordable cellulosic ethanol. Nat Rev Genet 2008, 9:433-443.

55. Vogel J, Hill T: High-efficiency Agrobacterium-mediated transformation of Brachypodium distachyon inbred line Bd21-3. Plant Cell Rep 2008, 27:471-478.
56. Clough SJ, Bent AF: Floral dip: a simplified method for Agrobacterium-mediated transformation of Arabidopsis thaliana. Plant J 1998, 16:735-743.

57. Hong SY, Lee S, Seo PJ, Yang MS, Park CM: Identification and molecular characterization of a Brachypodium distachyon GIGANTEA gene: functional conservation in monocot and dicot plants. Plant Mol Biol 2010, 72:485-497.

58. Oh SA, Park JH, Lee Gl, Paek KH, Park SK, Nam HG: Identification of three genetic loci controlling leaf senescence in Arabidopsis thaliana. Plant J 1997, 12:527-535.

doi:10.1186/1471-2229-14-15

Cite this article as: Ryu et al:: Molecular and functional characterization of cold-responsive C-repeat binding factors from Brachypodium distachyon. BMC Plant Biology 2014 14:15.

\section{Submit your next manuscript to BioMed Central and take full advantage of:}

- Convenient online submission

- Thorough peer review

- No space constraints or color figure charges

- Immediate publication on acceptance

- Inclusion in PubMed, CAS, Scopus and Google Scholar

- Research which is freely available for redistribution

Submit your manuscript at www.biomedcentral.com/submit
C Biomed Central 